\title{
Intervenção farmacêutica no uso indiscriminado da ivermectina: um estudo comparativo
}

\author{
Pharmaceutical intervention in the indiscriminate use of ivermectin: a comparative study \\ Intervención farmacéutica en el uso indiscriminado de ivermectina: un estudio comparativo
}

Recebido: 24/08/2021 | Revisado: 30/08/2021 | Aceito: 31/08/2021 | Publicado: 02/09/2021

\author{
Elismar dos Santos Souza \\ ORCID: https://orcid.org/0000-0001-7598-0718 \\ Faculdade Integrada Carajás, Brasil \\ E-mail: elismar2626@gmail.com \\ Weslayny Pereira Martins \\ ORCID: https://orcid.org/0000-0002-3229-108X \\ Faculdade Integrada Carajás, Brasil \\ E-mail: weslayny2016@outlook.com \\ Yolanda de Jesus Morais \\ ORCID: https://orcid.org/0000-0001-7105-8267 \\ Faculdade Integrada Carajás, Brasil \\ E-mail: yolandamorais123@gmail.com
}

\begin{abstract}
Resumo
Introdução: O mundo inteiro ainda passa pela emergência sanitária provocada pela pandemia do novo coronavírus SARS-Cov-2, recentemente, a ivermectina, anteriormente demonstrada como tendo atividade antiviral de amplo espectro in vitro, demonstrou ser um inibidor do vírus SARS-CoV-2, nesse cenário o artigo tem como objetivo analisar a atuação farmacêutica em drogarias, e comparar o padrão de consumo do medicamento Ivermectina no período da pandemia de Covid-19 no município de Redenção-PA. Métodos: Foi realizado um estudo exploratório, descritivo retrospectivo, sendo o procedimento metodológico documental na avaliação dos registros de vendas de 05 (cinco) drogarias na cidade de Redenção-PA sobre o uso indiscriminado de ivermectina durante a pandemia. $\mathrm{O}$ estudo foi realizado através da revisão dos relatórios de vendas expedidos em 3 (três) meses, sendo estes: Março/Abril/Maio de 2019/2020/2021, respectivamente. Resultados e discussão: Foi observado durante o estudo um salto no consumo de ivermectina no ano de 2020, devida intensa procura por medidas curativas ou preventivas da Covid-19. Em contrapartida registramos uma queda de vendas dessa medicação no ano de 2021, devido a vacinação no Brasil e realização de estudos que, ressaltam que em nenhum deles foi comprovada a ação in vivo da medicação. Considerações Finais: Cabe ao farmacêutico, o último elo entre a medicação e o paciente, orientar e prevenir sobre o uso indiscriminado de ivermectina, uma vez que há dados suficientes para abandonar o uso dessas medicações, por provas contundentes de que não ajudam no tratamento.
\end{abstract}

Palavras-chave: Ivermectina; Farmacêutico; Covid-19.

\begin{abstract}
Introduction: The whole world is still experiencing a health emergency caused by the pandemic of the new SARSCov-2 coronavirus, recently, ivermectin, previously shown to have broad-spectrum antiviral activity in vitro, has been shown to be an inhibitor of the SARS-CoV-2 virus, in this scenario, the article aims to analyze the pharmaceutical performance in drugstores, and compare the pattern of consumption of the drug Ivermectin in the period of the Covid19 pandemic in the city of Redenção-PA. Methods: An exploratory, retrospective descriptive study was carried out, with the methodological documental procedure in the evaluation of sales records of 05 (five) drugstores in the city of Redenção-PA on the indiscriminate use of ivermectin during the pandemic. The study was carried out by reviewing the sales reports issued in 3 (three) months, namely: March/April/May 2019/2020/2021, respectively. Results and discussion: During the study, a jump in the consumption of ivermectin was observed in 2020, due to the intense search for curative or preventive measures by Covid-19. On the other hand, we recorded a drop in sales of this medication in 2021, due to vaccination in Brazil and the performance of studies that highlight that in none of them the in vivo action of the medication was proven. Final Considerations: It is up to the pharmacist, the last link between the medication and the patient, to guide and prevent the indiscriminate use of ivermectin, since there is enough data to abandon the use of these medications, due to overwhelming evidence that they do not help in the treatment.
\end{abstract}

Keywords: Ivermectin; Pharmaceutical; Covid-19.

\section{Resumen}

Introducción: El mundo entero sigue experimentando una emergencia sanitaria provocada por la pandemia del nuevo coronavirus SARS-Cov-2, recientemente se ha demostrado que la ivermectina, previamente demostrada con actividad 
antiviral de amplio espectro in vitro, es un inhibidor de la Virus SARS-CoV-2, en este escenario, el artículo tiene como objetivo analizar el desempeño farmacéutico en las farmacias, y comparar el patrón de consumo del fármaco Ivermectina en el período de la pandemia Covid-19 en la ciudad de Redenção-PA. Métodos: Se realizó un estudio exploratorio, descriptivo retrospectivo, con el procedimiento documental metodológico en la evaluación de registros de ventas de 05 (cinco) farmacias de la ciudad de Redenção-PA sobre el uso indiscriminado de ivermectina durante la pandemia. El estudio se llevó a cabo revisando los informes de ventas emitidos en 3 (tres) meses, a saber: marzo / abril / mayo 2019/2020/2021, respectivamente. Resultados y discusión: Durante el estudio se observó un salto en el consumo de ivermectina en 2020, debido a la intensa búsqueda de medidas curativas o preventivas por parte de Covid-19. Por otro lado, registramos una caída en las ventas de este medicamento en 2021, debido a la vacunación en Brasil y la realización de estudios que resaltan que en ninguno de ellos se comprobó la acción in vivo del medicamento. Consideraciones finales: Corresponde al farmacéutico, último vínculo entre el medicamento y el paciente, orientar y prevenir el uso indiscriminado de ivermectina, ya que existen datos suficientes para abandonar el uso de estos medicamentos, debido a la abrumadora evidencia de que lo hacen. no ayuda en el tratamiento.

Palabras clave: Ivermectina; Farmacéutica; Covid-19.

\section{Introdução}

O mundo inteiro ainda passa pela emergência sanitária provocada pela pandemia do novo coronavírus SARS-Cov-2, o vírus é capaz de causar uma intensa agressão pulmonar pela resposta inflamatória desencadeada, e em questão de dias pode evoluir para insuficiência respiratória (Silva et al., 2020). Nesse cenário, não existem planos estratégicos prontos, detalhados e indefectíveis a serem aplicados frente à pandemia de coronavírus - tudo é inédito (Silva; Castiel, 2020), pesquisadores de todas as partes tem se esforçado na procura de medicamentos já existentes que possam ter ação contra a COVID-19 (Silva et al., 2020).

O COVID-19, trata-se de ácido ribonucléico (RNA) vírus envelopados, habitualmente encontrados em humanos, outros mamíferos e aves, podendo ocasionar doenças respiratórias, entéricas, hepáticas e neurológicas (Rodrigues; Silva, 2020). Em relação às formas de apresentação da Covid-19, elas podem variarde um simples resfriado, a uma pneumonia severa, que tem como sintomas mais comuns (associados ou não): a sensação febril ou febre, dor de garganta, dor de cabeça, tosse, coriza, perda de olfato (anosmia), alteração do paladar (ageusia), cansaço, dispneia, distúrbios gastrointestinais e diminuição de apetite (Huang et al.,2020).

Recentemente, a ivermectina, anteriormente demonstrada como tendo atividade antiviral de amplo espectro in vitro, demonstrou ser um inibidor do vírus SARS-CoV-2, com uma redução de 5000 vezes no RNA viral em 48 h (Caly et al., 2020). Porém, é importante considerar que o fato de um medicamento apresentar atividade in vitro para determinado microrganismo não quer dizer que seja bem-sucedido o tratamento in vivo (Chaves, 2020).

A atuação do farmacêutico no processo é fundamental para prevenir os danos causados pelo uso irracional de medicamentos (Messias, 2015), vale salientar que,segundo a OMS, mais de 50\% de todos os medicamentos são incorretamente prescritos, dispensados e vendidos; e mais de 50\% dos pacientes os usam incorretamente. O uso abusivo, insuficiente ou inadequado de medicamentos lesa a população e desperdiça os recursos públicos (Brasil, 2012). Portanto, durante a dispensação, é imprescindível que o farmacêutico forneça orientações necessárias que irão compreender toda a logística do uso correto de medicamentos, indo desde aavaliação da prescrição até o acondicionamento correto dos mesmos na farmácia caseira (Messias, 2015).

Este estudo, logo, justifica-se pelo fato do uso indiscriminado de ivermectina que boa parte da população está se submetendo influenciada por informações incompletas. Na esperança de cura multidões recorreram a farmácia no intuito de obter uma profilaxia, ou de diminuir os sintomas da Covid-19, cabendo ao farmacêutico redirecionar esses pacientes, instruindo-os de maneira correta, e garantindo a segurança da população. Portanto, o objetivo desse artigo é analisar a atuação farmacêutica em drogarias, e comparar o padrão de consumo do medicamento Ivermectina no período da pandemia de Covid19 no município de Redenção-PA. 


\section{Metodologia}

Foi realizado um estudo exploratório, descritivo retrospectivo Estrela (2018), sendo o procedimento metodológico documental na avaliação dos registros de vendas de 05 (cinco) drogarias na cidade de Redenção-PA sobre o uso indiscriminado de ivermectina durante a pandemia. O estudo foi realizado através da revisão dos relatórios de vendas expedidos em 3 (três) meses, sendo estes divididos em: período anterior a pandemia (Março/Abril/Maio de 2019), assim que o Covid-19 foi considerado mundialmente disseminado (Março/Abril/Maio de 2020), e atualmente (Março/Abril/Maio de 2021).

Pesquisas Envolvendo Seres Humanos, este projeto não foi submetido à apreciação ética do CEP em Seres Humanos Após a coleta, os dados foram organizados em gráficos e tabelas para análise e interpretação dos resultados. Foi utilizado como critério de inclusão: apenas o medicamento ivermectina, durante o período especificado. Os dados obtidos foram organizados tabulados com o auxílio do programa Microsoft Office Excel 2016.

\section{Resultados e Discussão}

Atualmente, a maior promessa e expectativa global para a ivermectina é o uso contra o Sars-CoV-2, responsável pela síndrome respiratória aguda grave, tornando-se um potencial candidato ao tratamento da COVID-19 (Caly et al., 2020). O reaproveitamento de medicamentos é uma alternativa rápida, já que em geral, são medicamentos que tem seu uso aprovado, bem estabelecido e seguro. Dentre essesmedicamentos, a ivermectina poderia ser uma alternativa terapêutica (Choudhary et al., 2020).

A ivermectina é um dos fármacos antiparasitários mais conhecidos e amplamente utilizados na medicina humana e veterinária (Laing et al., 2017). De início, a ivermectina foi identificada como um inibidor da interação entre a proteína integrase do vírus da imunodeficiência humana-1 (HIV-1) e o heterodímero alfa / beta1da importina responsável pela importação nuclear de proteína integrase (Espreafico Junior et al., 2020). Associado a esse mecanismo de ação, outro fator que contribui para a decisão em implementar a ivermectina em diversas terapêuticas consiste no seu baixo custo monetário. Por estas razões, a ivermectina foi incluída na $21^{\mathrm{a}}$ lista de Medicamentos Essenciais da OMS (Rizzo, 2020).

O volume de vendas registrados em Redenção-PA durante o período escolhido foi de 1284 unidades de ivermectina. Podemos verificar de acordo com a Figura 1, a variação de vendas conforme a pandemia ia se intensificando, sendo que,no mês de março de 2019 registramos que houve apenas 27 unidades vendidas, um ano depois, em março de 2020, notamos um recorde de vendas, totalizando 441 vendas da mesma medicação. 
Figura 1: Variação das vendas de Ivermectina durante a pandemia.

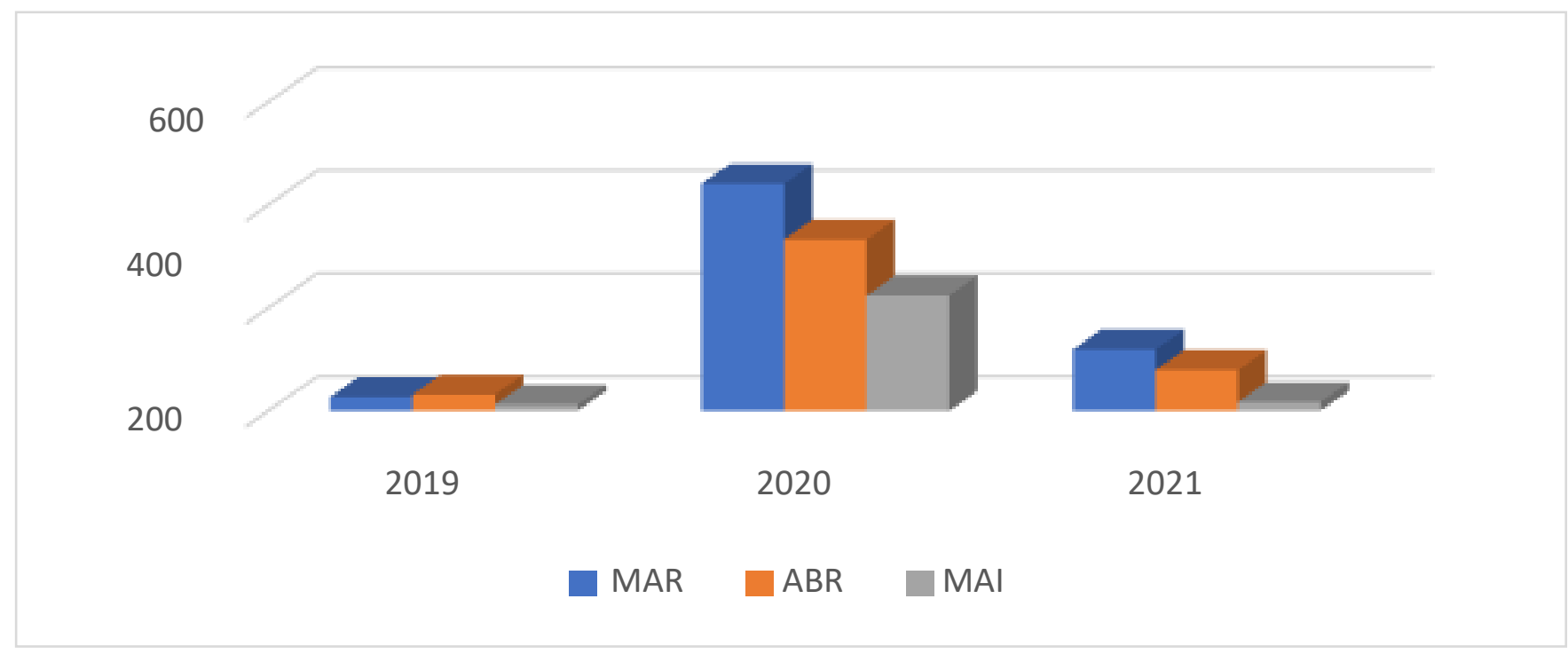

Fonte: Dados da pesquisa (2021).

Em virtude do crescente uso do medicamento, a Agência Nacional de Vigilância Sanitária - Anvisa se posicionou contra o uso rotineiro da ivermectina comotratamento e prevenção a COVID-19. A mesma determinou através da RDC 405 de 22 de julho de 2020 que a dispensação de ivermectina deveria ser realizada com retenção de receita. Porém a dispensação nas farmácias continuou elevada, levandoa Anvisa a liberação da dispensação sem retenção de receitas através da RDC 420 de 01 de setembro de 2020 (Oliveira, 2020).

Evidencia-se que a automedicação é um hábito no Brasil, sendo ele preocupante em qualquer época, mas que por conta do pânico instalado pelo isolamento social e pela veiculação de notícias infelizes acentuou-se significativamente (SILVA et al., 2020). De acordo com Oliveira (2020), um estudo sobre possíveis medicamentos para o tratamento do COVID-19 concluiu que não existem dados disponíveis para sugerir qualquer tratamento para erradicação da doença a ser utilizado no nível clínico.

Dessa forma, tornam-se necessárias políticas públicas que diminuam o consumo dessas drogas, que no geral, podem acabar fortalecendo a estrutura viral ou causando complicações nos indivíduos que delas fizerem uso, ao invés de imunizá-los (Silva et al., 2020).

O uso indiscriminado da Ivermectina põe em risco a saúde dos usuários que utilizam a medicação de forma aleatória, motivados pelo populismo, adesão do Sistema Único de Saúde - SUS à medicação e resultados bem-sucedidosdo estudo in vitro, levando a população à busca pela medicação e criação de protocolos de tratamento sem evidências clínicas e cientificas (Oliveira, 2020).

\subsection{Intervenção farmacêutica frente ao uso indiscriminado de ivermectina}

De acordo com Person et al. (2021), o medo e a necessidade mesclada de angústia promoveram uma guerra desesperada na busca por um tratamento eficaz contra o novo coronavírus. Apesar da falta de evidências do emprego de ivermectina contra a Covid-19, o número de dispensações em março de 2020 aumentou 1533,33\% em comparação ao mesmo período no ano anterior, como pode ser visto na Figura 2. 
Figura 2: Comparativo de vendas entre 2019 e 2020

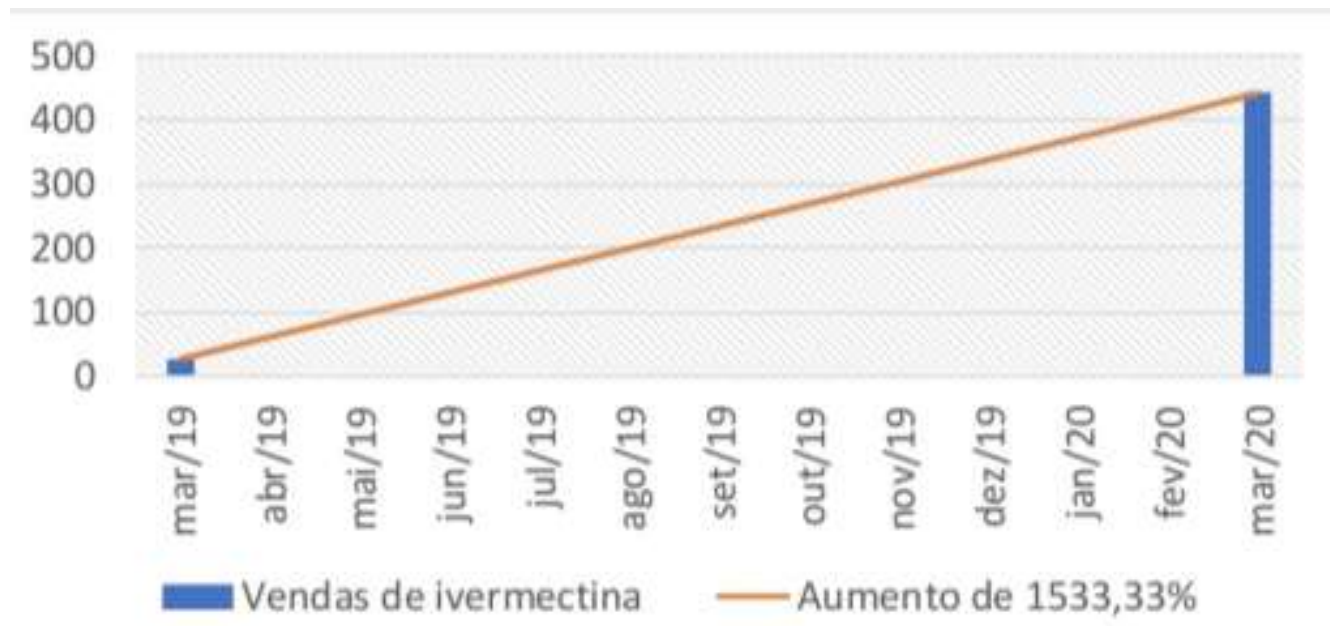

Fonte: Dados da pesquisa (2021).

$\mathrm{Na}$ vigência de mortalidade crescente e diante da pandemia, tornou -se necessária uma maior rapidez em instituir terapêutica e essa, inevitavelmente, esbarrou em pontos cruciais que vão de encontro ao estabelecimento da efetividade e segurança (Person et al., 2021).

O uso incorreto de medicamentos é um dos maiores problemas de Saúde Pública em todo mundo. Segundo estimativas da Organização Mundial de Saúde (OMS), cerca de metade dos medicamentos são prescritos, dispensados e vendidos incorretamente (Who, 2002).

Um ponto crucial nessa busca desregrada de Ivermectina se deu devido a propagação de falsas notícias a respeito de sua eficácia em redes sociais (Whatsapp, Youtube e Facebook), em sua grande maioria a medicação se apresentava como medida preventiva contra a Covid-19, disseminando informações aos consumidores, de forma menos explícita, afirmando estar promovendo a saúde (Cabezas, 2000).

Prefeituras e drogarias chegaram a dispensar, no auge da pandemia, o chamado "kit-covid", um mesclado de medicamentos com pouca ou nenhuma 0100200300400500 mar/19 abr/19 mai/19 jun/19 jul/19 ago/19 set/19 out/19 nov/19 dez/19 jan/20 fev/20 mar/20 Vendas de ivermectina Aumento de 1533,33\% comprovação científica, generalizando os pacientes e excluindo as necessidades fisiológicas de cada indivíduo. Todos esses fatores, somando-se a propaganda de medicamentos, se tornaram um estímulo frequente ao uso inadequado da Ivermectina. Sobretudo, ao ressaltar benefícios e minimizar a possibilidade de efeitos adversos. O posicionamento da OMS e OPAS é fortemente contrário ao uso da ivermectina para quaisquer outros propósitos distintos dos quais seu uso está devidamente autorizado (OPAS, 2020).

Uma vez que, de acordo com Chaves (2020), os efeitos adversos documentados incluem: reações dermatológicas, gastrointestinais, neuromusculares e cardiovasculares. A partir do segundo semestre de 2020, observamos o lançamento de renomados estudos científicos relacionando a ivermectina ao Covid-19, percebeu-se paralelamente uma queda em suas vendas em todo Brasil, inclusive em Redenção PA (Figura 3). Isso se deve aos meios de comunicação (TV, rádio, revistas e internet), responsáveis pela propagação desses estudos, afirmarem cada vez mais a falta de comprovações da ação da medicação in vivo. 
Figura 3: Comparativo de vendas entre 2020 e 2021

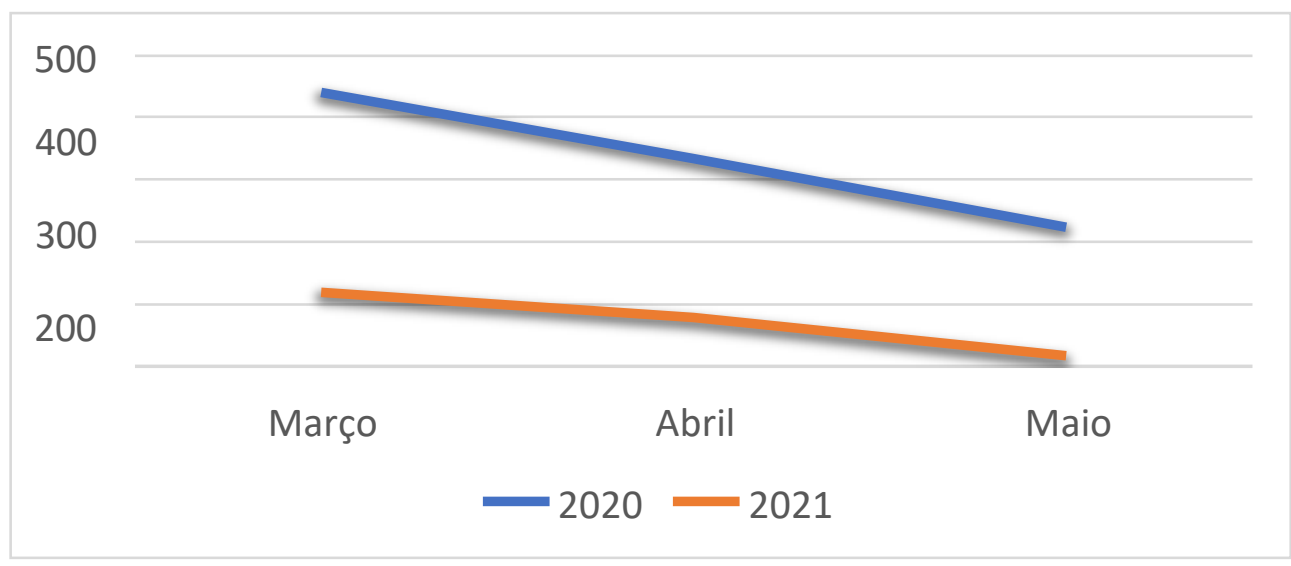

Fonte: Dados da pesquisa (2021).

Outro aspecto a ser considerado, foi o começo da vacinação em território nacional contra a Covid-19 no primeiro semestre de 2021, apesar de ser iniciada na população idosa (90 anos +) e considerada "de risco", todos se sentiram mais seguros e recorreram menos a medicação. Mesmo quando houve um novo pico de mortes em virtude da variante indiana de Covid-19 (Figura 4), as vendas de ivermectina se mantiveram em queda.

Figura 4: Comparação de mortes por Covid-19 por mês no Brasil.

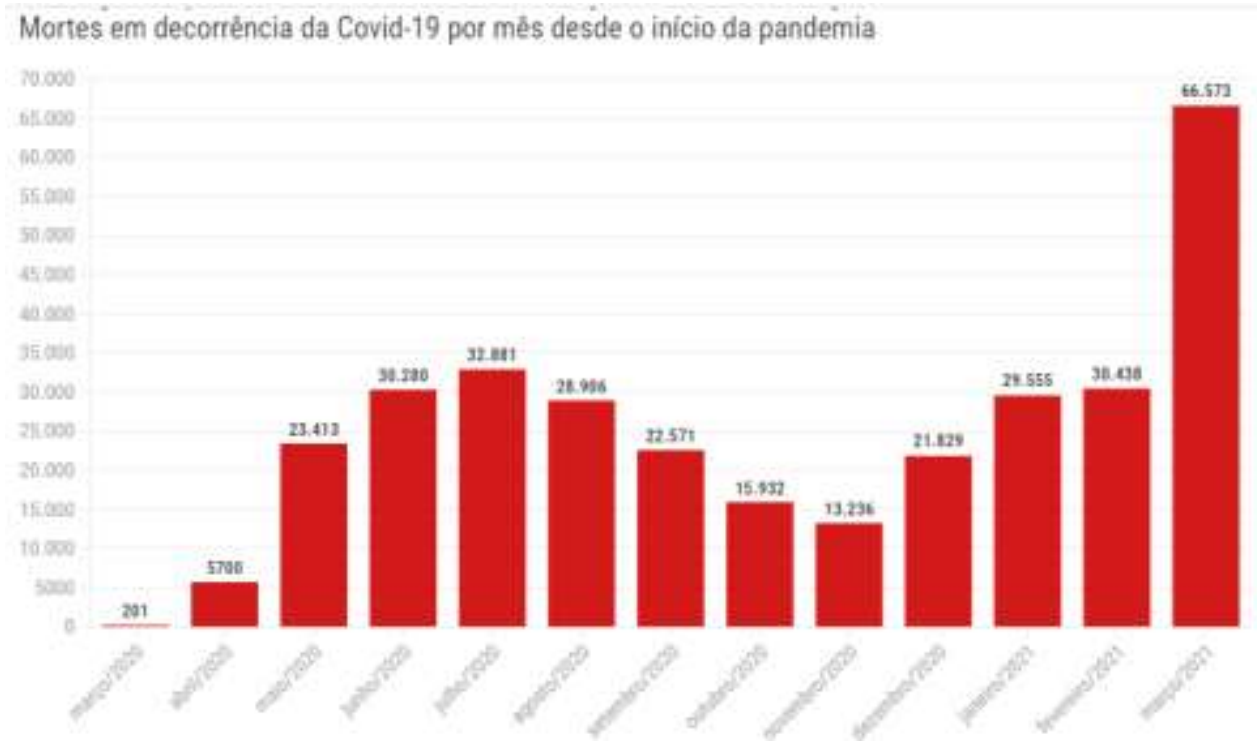

Fonte: CNN (2021).

O grande desafio da pandemia da Covid-19 foi a velocidade com que a doença se espalhou e, tão rápido quanto ela, a disseminação de notícias/informações, sejam elas verdadeiras ou falsas, que muitas vezes geraram pânico e comportamentos de risco, entre eles, a automedicação. Dessa maneira, o farmacêutico, dentro de suas habilitações e possibilidades, deve estar preparado para atuar de maneira adequada, executando a atenção farmacêutica sempre a favor do paciente (Galato et al., 2008).

A população, normalmente, tem fácil acesso ao profissional farmacêutico, o qual está habilitado para atuar como agente sanitário, e sua função não deve se limitar apenas à dispensação, devendo atuar de acordo com seu amplo conhecimento em favor do paciente (Vidotti; Hoefler, 2006). O farmacêutico, como um profissional capaz de interagir com os prescritores e 
os pacientes, deve possuir o quesito informação como alicerce desta relação. A informação repassada deve ser confiável e baseada em evidências (Galato et al.,2008).

De acordo com Martins e Reis (2020), considerando o contexto da pandemia de Covid-19, fica evidente a necessidade do farmacêutico incorporar na sua prática os referenciais teóricos da farmacoepidemiologia e da avaliação de tecnologias em saúde para assegurar um cuidado baseado em evidências. Uma vez que, o contexto da prática farmacêutica, que é um serviço fundamental, tem como preocupação o bem estar do paciente e passa a ser o foco principal das ações, o farmacêutico assume papel fundamental, unindo seus conhecimentos aos de outros profissionais de saúde e aos da comunidade para a promoção da saúde (Vieira, 2010).

\section{Considerações Finais}

Diante da situação emergencial em saúde que temos vivenciado em função da pandemia, e até que tenhamos o registro de um medicamento com indicação para tratamento da Covid-19, o ideal é que a proposição de terapias medicamentosas off label (aquelas em que se utilizam materiais ou fármacos fora das indicações em bula ou protocolos) tomem por base evidências de estudos científicos com o maior rigor metodológico possível.

Uma dessas drogas propostas para a possível prevenção do novo coronavírus é a ivermectina, uma droga segura, usada há muitos anos. Os casos de toxicidade são raros. Contudo, o problema na pandemia é que ela passou a ser entendida como uma solução para um mal para o qual ela não foi indicada e não tem, até o momento, nenhuma comprovaçãocientífica.

Durante o estudo observamos um salto nas vendas de ivermectina no ano de 2020 em comparação aos demais períodos, justificando-se pela disseminação de falsas notícias ligadas a estudos envolvendo a medicação. Ao final do ano de 2020 iniciaram-se diversos estudos científicos, e mesmo sendo relacionada in vitro com a Covid-19, a ivermectina não foi indicada para terapia in vivo com seres humanos.

O Brasil iniciou a sua vacinação em 2021, acompanhando tendencias mundiais, diminuindo o frenesi em relação a procura de medicamentos "preventivos ou curativos" contra a Covid-19, uma vez que a população se sentiu mais segura, e que os meios de comunicação intensificaram a propagação sobre a fragilidade dos estudos envolvendo a ivermectina e demais medicamentos.

Ressaltamos que nenhum medicamento deve ser dispensado sem a devida prescrição médica e acompanhamento farmacoterapêutico, feito pelo farmacêutico. Sabemos que o uso indiscriminado de medicamentos é aquele feito sem critério, de forma abusiva e na maioria das vezes oriundo da automedicação. Portanto, cabe ao farmacêutico, o último elo entre a medicação e o paciente, orientar e prevenir sobre o uso indiscriminado de ivermectina, uma vez que há dados suficientes para abandonar o uso dessas medicações, por provas contundentes de que não ajudam no tratamento e também podem estar implicadas em riscos adicionais não desprezíveis, nesse sentido recomenda-se a necessidade de estudos complementares em relação a prevenção do uso indiscriminado da ivermectina.

\section{Referências}

Brasil. (2012). Ministério da Saúde. Secretaria de Ciência, Tecnologia e Insumos Estratégicos. Uso racional de medicamentos, temas selecionados, 9. http://biblioteca.cofen.gov.br/uso-racional-de-medicamentos-temas-selecionados/.

Cabezas Yaru, V. P., Ormeño Mondaca, E. A., \& Pablaza Vargas, L. D. C. (2000). Automedicación de analgésicos no narcóticos: consultório. Santo Tomás. http://bases.bireme.br/cgibin/wxislind.exe/iah/online/?IsisScript=iah/iah.xis\&src=google\&base=LILACS\&lang=p\&nextAction=lnk\&exprSearc $\mathrm{h}=284702 \&$ indexSearch=ID.

Caly, L., Druce, J. D., Catton, M. G., Jans, D. A. \& Wagstaff, K. M. (2020). O medicamento aprovado pela FDA ivermectina inibe a replicação do SARSCoV-2 in vitro. Antiviral research, 178, 104787. https://www.sciencedirect.com/science/article/pii/S0166354220302011. 
Chaves, E. F. (2020). Considerações sobre os medicamentos com potencial efeito farmacológico para o vírus sars-hcov-2 do departamento de farmácia da associação de medicina intensiva brasileira - amib. https://www.amib.org.br/fileadmin/user_upload/amib/2020/abril/16/Consideracoes_so bre_os_medicamentos_com_potencial_efeito_farmacologico_para_o_virus_SARS-HCoV-2_pelo_Departamento_de_Farmacia_AMIB_.pdf.

Choudhary., R. \& Sharma, AK (2020). Uso potencial de drogas hidroxicloroquina, ivermectina e azitromicina no combate ao COVID-19: tendências, escopo e relevância. Novos micróbios e novas infecções , 35 , 100684: https://pubmed.ncbi.nlm.nih.gov/32322397/.

CNN. 1 a cada 5 brasileiros vítimas da Covid-19 morreu em Março de 2021. 2021. https://www.cnnbrasil.com.br/saude/2021/04/01/1-a-cada-5- brasileirosvitima-da-covid-19-morreu-em-marco-de-2021.

Junior, C. R. E., do Nascimento Antonio, M. V., Imperador, C. H. L., Chin, C. M., \& Bosquesi, P. L. (2020). Remdesivir, nitazoxanida e ivermectina na COVID-19. Ulakes Journal of Medicine, 1, 74-80: http://revistas.unilago.edu.br/index.php/ulakes/article/view/259.

Galato, D., Alano, G. M., Trauthman, S. C., \& Vieira, A. C. (2008). A dispensação de medicamentos: uma reflexão sobre o processo para prevenção, identificação e resolução de problemas relacionados à farmacoterapia. Revista Brasileira de Ciências Farmacêuticas, 44, 465-475. https://www.scielo.br/scielo.php?pid=S1516-93322008000300017\&script=sci_abstract\&tlng=pt..

Huang, C., Wang, Y., Li, X., Ren, L., Zhao, J., Hu, Y., \& Cao, B. (2020). Clinical features of patients infected with 2019 novel coronavirus in Wuhan, China. The lancet, 395(10223), 497-506. https://www.thelancet.com/journals/lancet/article/PIIS0140-67362030183-5/fulltext.

Laing, R., Gillan, V., \& Devaney, E. (2017). Ivermectina - droga velha, novos truques? Trends in parasitology, 33 (6), 463-472. https://pubmed.ncbi.nlm.nih.gov/28285851/.

MARTINS, M. A. (2020). Pharmacists in response to the COVID-19 pandemic in Brazil: where are we? Revista Brasileira de Farmácia Hospitalar e Serviços de Saúde, 11(3), 517-517: Martins/publication/344328879_Editorial_O_farmaceutico_no_enfrentamento_da_C OVID19_no_Brasil_onde_estamos_Version_in_Portuguese/links/5f68950292851c14bc8be 1fb/Editorial-O-farmaceutico-no-enfrentamento-da-COVID-19-noBrasil-onde- estamos-Version-in-Portuguese.pdf.

MCF, M. (2015). Atenção farmacêutica no uso racional de medicamentos. Sci Health,6(1), 7-14. http://arquivos.cruzeirodosuledu cacional.edu.br/principal/new/revista_scienceinhealth.

Oliveira, F. C. A. (2020). Análise preliminar da dispensação de ivermectina, em tempos de COVID-19, em farmácia de manipulação. 15 f. Trabalho de Conclusão de Curso (Graduação em Farmácia) - Departamento de Farmácia, Centro de Ciências da Saúde, Universidade Federal do Rio Grande do Norte, Natal. https://monografias.ufrn.br/jspui/handle/123456789/10819.

Opas. Recomendação sobre o uso de ivermectina no tratamento de COVID. https://iris.paho.org/bitstream/handle/10665.2/52462/OP ASIMSCDECOVID19200033_por.pdf?sequence=1\&isAllowed=y.

PersonI, O. C., dos Santos PugaII, M. E., do AmaralIII, J. L. G., \& AtallahIV, Á. N. (2021). Intervenção com ivermectina para COVID-19 (SARS-CoV-2): sinopse baseada em evidências. Revista diagnóstico e tratamento• volume 26• edição. http://associacaopaulistamedicina.org.br/assets/up loads/revista_rdt/2d8a7c864c3de3.

Rizzo, E. (2020). Ivermectin, antiviral properties and COVID-19: a possible new mechanism of action. Naunyn-schmiedeberg's Archives of Pharmacology, 393, 1153-1156: https://pubmed.ncbi.nlm.nih.gov/32462282/.

Rodrigues, N. H., \& da Silva, L. G. A. (2020). Gestão da pandemia coronavírus em um hospital: relato de experiência profissional/Management of the coronavirus pandemic in a hospital: professional experience report. Journal of Nursing and Health, 10(4): https://periodicos.ufpel.edu.br/ojs2/index.php/enfermagem/article/view/18530.

Silva, C. Y. A. B., Ponciano, A. K. B \& Luz, D. C. R. P. (2020). Automedicação durante a pandemia de Covid-19. Revista e-ciência. 3(9). http://www.revistafjn.com.br/revista/index.php/eciencia/article/view/967.

Silva, J. N. B., Brito, M. E. S., Júnior, D. A. S \& Silva, A. S. (2020). A ivermectina possui ação terapêutica na Covid-19? Anais do Congresso de Geriatria e Gerontologia UNIFACIG. 1(1). http://pensaracademico.facig.edu.br/index.php/congressogeriatria/article/view/2317\#:.

Silva, A. D., Silva, A., \& Mendes, P. (2020). Boletim BiblioCovid: notícias falsas (fake news) e COVID-19.

Vasconcellos-Silva, P. R., \& Castiel, L. D. (2020). COVID-19, as fake news e o sono da razão comunicativa gerando monstros: a narrativa dos riscos e os riscos das narrativas. Cadernos de Saúde Pública, 36: https://www.scielo.br/scielo.php?script=sci_arttext\&pid=S0102-311X2020000703001.

Vidotti, C. C. F \& Hoefler, R. (2006). Apoio a transformação do exercício profissional do farmacêutico na farmácia comunitária. Boletim Farmacoterapêutica. Brasília, 11(1), 1-5. https://www.cff.org.br/sistemas/geral/revista/pdf/14/farmacoterapeutica.pdf.

Vieira, F. S. (2010). Assistência farmacêutica no sistema público de saúde no Brasil. Revista Panamericana de Salud Pública,27, 149-156. http://bvsms.saude.gov.br/bvs/is_digital/is_0210/pdfs/IS30\%282\%29034.pdf .

WHO. (2002). Promoting rational use of medicines: core components. Promoción del uso racional de medicamentos: componentes centrales. https://apps.who.int/iris/handle/10665/67438. 